Sädhanā Vol. 37, Part 1, February 2012, pp. 3-15. (C) Indian Academy of Sciences

\title{
Effect of loading condition, specimen geometry, size-effect and softening function on double- $K$ fracture parameters of concrete
}

\author{
SHAILENDRA KUMAR ${ }^{\mathrm{a}, \mathrm{b}}$ and S V BARAI ${ }^{\mathrm{c}, *}$ \\ ${ }^{a}$ Department of Civil Engineering, Institute of Technology, \\ Guru Ghasidas Vishwavidyalaya (A Central University), Bilaspur 495009, India \\ ${ }^{\mathrm{b}}$ Department of Civil Engineering, National Institute of Technology, \\ Jamshedpur 831014, India \\ ${ }^{\mathrm{c}}$ Department of Civil Engineering, Indian Institute of Technology, \\ Kharagpur 721 302, India \\ e-mail: shailendrakmr@yahoo.co.in; skbarai@civil.iitkgp.ernet.in
}

\begin{abstract}
This paper presents numerical investigation of the influence of the specimen geometry, loading condition, size-effect and softening function of concrete on double- $K$ fracture parameters. The input data needed for computation of the double$K$ fracture parameters are obtained from the well-known version of Fictitious Crack Model (FCM). FCM is developed for three standard specimens: three-point bend test, compact tension specimen and four-point bend test of size range 100-600 $\mathrm{mm}$ at relative size of initial crack length 0.3 . The analysis of numerical results shows some interesting behaviour of double- $K$ fracture parameters.
\end{abstract}

Keywords. Three-point bend test; four-point bend test; compact tension test; cohesive stress; double- $K$ fracture parameters; size-effect; weight function.

\section{Introduction}

The application of linear elastic fracture mechanics (LEFM) concept to concrete was first attempted in the early 1960s and thereafter tremendous advancement took place in the field of fracture mechanics of concrete. In the past, it has been shown that LEFM cannot be directly applied to study the crack propagation phenomena in concrete because of a large and variable size of fracture process zone that exists ahead of a macro-crack when the specimen is loaded. This resulted in development of several nonlinear fracture models based on two basic approaches: first using numerical approach such as cohesive crack model (CCM) or fictitious crack model (FCM) (Hillerborg et al 1976; Petersson 1981; Carpinteri 1989; Planas \& Elices 1991) and crack band model (CBM) (Bažant \& Oh 1983) and the second using modified LEFM concept such as two parameter fracture model (TPFM) (Jenq \& Shah 1985), size effect model (SEM) (Bažant et al 1986), effective crack model (ECM) (Nallathambi \& Karihaloo 1986),

*For correspondence 
$K_{R}$-curve method based on cohesive force distribution (Xu \& Reinhardt 1998, 1999a), double$K$ fracture model (DKFM) (Xu \& Reinhardt 1999a, b) and double- $G$ fracture model (DGFM) (Xu \& Zhang 2008).

The fracture models attributed to modified LEFM concept such as DKFM, DGFM and the $K_{R}$-curve method associated with cohesive force distribution can capture three important stages of crack propagation in concrete: crack initiation, stable crack propagation and unstable crack propagation while the other models under the same category such as TPFM, SEM and ECM predict the fracture loads at critical condition only. The DKFM is characterized by two material parameters: initial cracking toughness $K_{I C}^{i n i}$ and unstable fracture toughness $K_{I C}^{u n}$. The first parameter termed as initial cracking toughness $K_{I C}^{i n i}$ is directly calculated by the initial cracking load and initial notch length using linear elastic fracture mechanics formula. The second parameter known as unstable fracture toughness $K_{I C}^{u n}$ can be obtained by peak load and corresponding effective crack length using the same linear elastic fracture mechanics formula. The cohesive toughness $K_{I C}^{C}$ is determined to obtain the value of $K_{I C}^{i n i}$ using analytical method. Both the characteristic fracture parameters $K_{I C}^{i n i}$ and $K_{I C}^{u n}$ of DKFM are useful for crack propagation study of concrete structures. For some important structures such as concrete dam, concrete pressure vessel, nuclear reactor etc., the parameters $K_{I C}^{i n i}$ and $K_{I C}^{u n}$ are useful while the accurate prediction of $K_{I C}^{i n i}$ is needed to specialized structural elements such as liquid retaining concrete structures where knowledge of crack initiation is also of prime importance. Therefore, the parameter $K_{I C}^{i n i}$ can be used to assess the initial cracking toughness whereas the parameter $K_{I C}^{u n}$ can be useful to describe the critical unstable fracture of cracked structures. At the same time, determination of double- $K$ fracture parameters is experimentally easier to determine because the unloading and reloading of the structure is not needed. This averts the need of closed-loop testing arrangement. Based on fracture tests, Xu \& Reinhardt (1999a) determined the values of $K_{I C}^{i n i}$ and $K_{I C}^{u n}$ for three-point bend test (TPBT) and compact tension (CT) specimen geometries. In the study, it was reported that both the fracture parameters $K_{I C}^{i n i}$ and $K_{I C}^{u n}$ were dependent on material properties and independent of specimen geometry and size. Xu \& Reinhardt (1999b, c) developed analytical methods for TPBT and CT or wedge splitting test (WST) to determine the values of double- $K$ fracture parameters. From the available experimental results, it was also shown that double- $K$ fracture parameters $K_{I C}^{i n i}$ and $K_{I C}^{u n}$ were not dependent on size of the specimen. In addition, it was also shown that these fracture parameters were not significantly influenced by softening function of concrete. Xu \& Reinhardt (1999c) computed the material fracture parameters $K_{I C}^{i n i}$ and $K_{I C}^{u n}$ based on the fracture tests of small size wedge-splitting specimens. In the study it was observed that these fracture parameters were independent of the relative size of initial notch length and the thickness of specimens but they were slightly dependent on the specimen size. Zhao \& Xu (2002) reported numerical experiments on TPBT specimens with the objective to study the influence of span/depth ratio, specimen size and strength of concrete on double- $K$ fracture parameters. In the study, it was shown that the unstable fracture toughness was independent of the span/depth ratio and dependent on the material property whereas the initial fracture toughness varied with the strength of material, span/depth ratio and depth of specimen. Zhang et al (2007) carried out the fracture tests on a total of 43 concrete specimens (three-points bending beam and wedge splitting specimen) with the small-size aggregates being the maximum size of $10 \mathrm{~mm}$ for analysing the double- $K$ fracture parameters. The analysis of the results showed that the ratio of initial cracking load to maximum load was found to be in the range of $0.67-0.71$ and the ratio of initial fracture toughness to unstable fracture toughness was found to be in the range of 0.45-0.50. Xu \& Zhu (2009) conducted the fracture tests on different sizes of TPBT specimens made of hardening cement paste and mortar of different strengths. The test results showed that fracture behaviour of all cementitious composites, even hardening cement paste and 
mortar was nonlinear and the double- $K$ fracture model can also be applied to calculate the fracture parameters of these materials.

The experimental results and analysis available in the literature show that the double- $K$ fracture parameters are independent of specimen size and geometry. Several methods such as analytical method (Xu \& Reinhardt 1999b) and simplified approach (Xu \& Reinhardt 2000) are also available in literature for computing these fracture parameters. Recently the authors (Kumar \& Barai 2008, 2009a, 2010a) introduced the weight function method for determining the double- $K$ fracture parameters with better computational efficiency as well as without loss of accuracy. The authors (Kumar \& Barai 2008) showed that the double- $K$ fracture parameters were influenced by the specimen geometry, size-effect and the relative size of initial crack length. Prediction of size-effect from double- $K$ fracture parameters was also formulized in the subsequent study (Kumar \& Barai 2010b). It was further reported that the double- $K$ fracture parameters marginally depended on the loading condition (Kumar \& Barai 2009b). Some more results such as influence of softening function of concrete on the double- $K$ fracture parameters are addressed in the present paper and comprehensive results are thoroughly analysed.

The aim of the present study is to explore the dependency of the double- $K$ fracture parameters on the various loading and geometrical parameters in a precise manner. The input data needed for computation of the double- $K$ fracture parameters are obtained from the well-known version of Fictitious Crack Model. For this purpose, the FCM is developed for three standard specimens: TPBT, four-point bend test (FPBT) and CT specimen of size range 100-600 mm at initial crack length/depth $\left(a_{o} / D\right)$ ratio of 0.3 . The effect of specimen geometry and size-effect is investigated between the TPBT and CT specimen geometries whereas the effect of loading condition on the fracture parameters is investigated between the TPBT and FPBT. Finally, effect of softening function of concrete on the double- $K$ fracture parameters is studied using TPBT specimen.

\section{Dimensions of test specimens}

The present investigation is attributed to the determination of the double- $K$ fracture parameters for TPBT, FPBT and CT specimen (figure 1) for which the input data needed for computation are obtained from the FCM.

The standard dimensions of the TPBT (RILEM Technical Committee (50-FMC) 1985) are shown in figure 1(a) in which the symbols: $B, D$ and $S$ are the width, depth and span, respectively for TPBT geometry with $S / D=4$. The study for the effect of loading condition on the fracture parameters can be carried out by comparing the gained results between the TPBT and FPBT. In this case, two different loading conditions with the same specimen geometry in all respect can be obtained for precise comparison of loading effect on the fracture parameters. The loading and support conditions along with the dimensions of the FPBT considered in the study are shown in figure 1(b); in which, the symbols: $B, D$ and $S$ are the width, depth and support span, respectively with $S / D=4$ and moment $\operatorname{arm} L=D$. The load span is taken to be $2 \mathrm{D}$. This four-point bend specimen resembles exactly the same geometrical properties as of the standard three-point bending test geometry except for the difference in loading condition. The dimensions and configuration of standard CT specimen according to the ASTM standard E-399 (2006) are shown in figure 1(c). The dimensioning should comply $D_{1}=1.25 \mathrm{D}, H=0.6 \mathrm{D}, H_{1}=0.275 \mathrm{D}$ and the specimen thickness $B=0.5 \mathrm{D}$. The effect of specimen geometry on the fracture parameters can be investigated by comparing the results gained between the TPBT and CT specimen. 


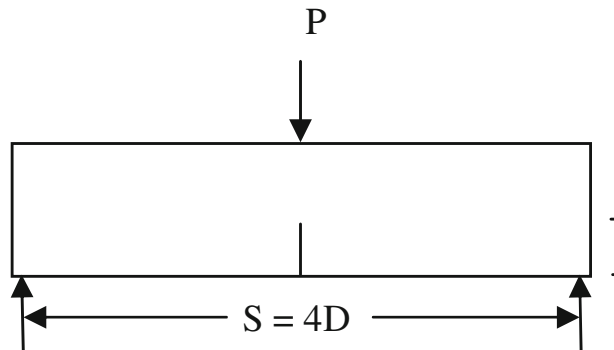

(i) Longitudinal section

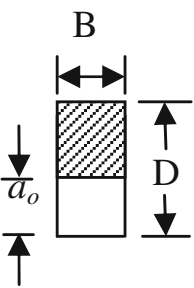

(ii) Mid span

(a) TPBT geometry

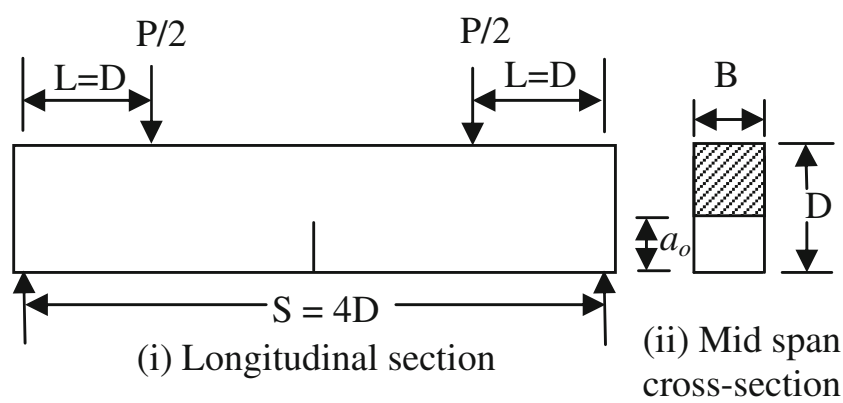

(b) FPBT specimen

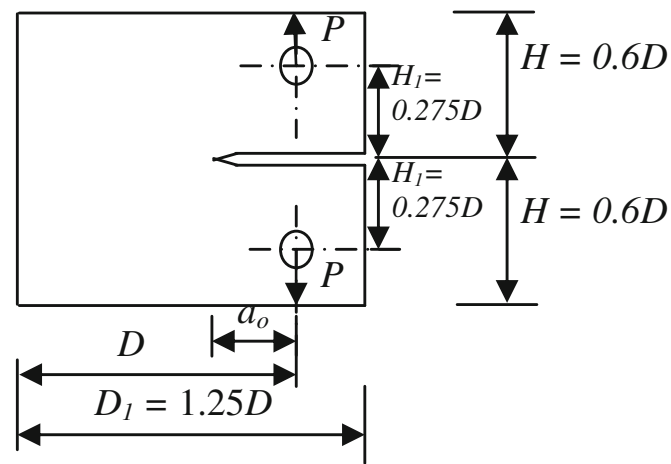

(c) CT specimen

Figure 1. Dimensions and loading schemes.

\section{Material properties and fictitious crack model}

Three material properties such as modulus of elasticity $E$, uniaxial tensile strength $f_{t}$, and fracture energy $G_{F}$ are required to describe the FCM or CCM (Hillerborg et al 1976; Petersson 1981; Carpinteri 1989; Planas \& Elices 1991; Kumar \& Barai 2009c). The FCM for TPBT, FPBT and CT specimens is developed in the present study. In this method, the governing equation of crack opening displacement (COD) along the potential fracture line is written. The influence of coefficients of the COD equation are determined using linear elastic finite element method. 


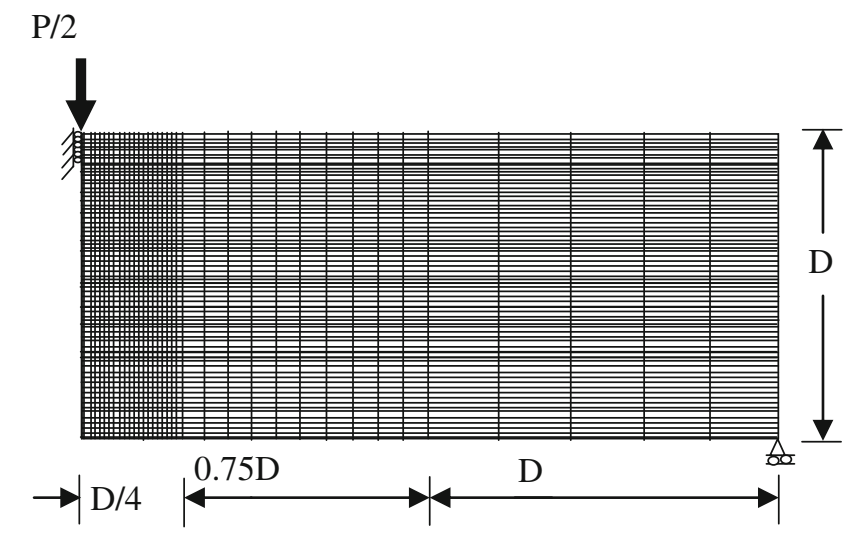

(a) TPBT specimen

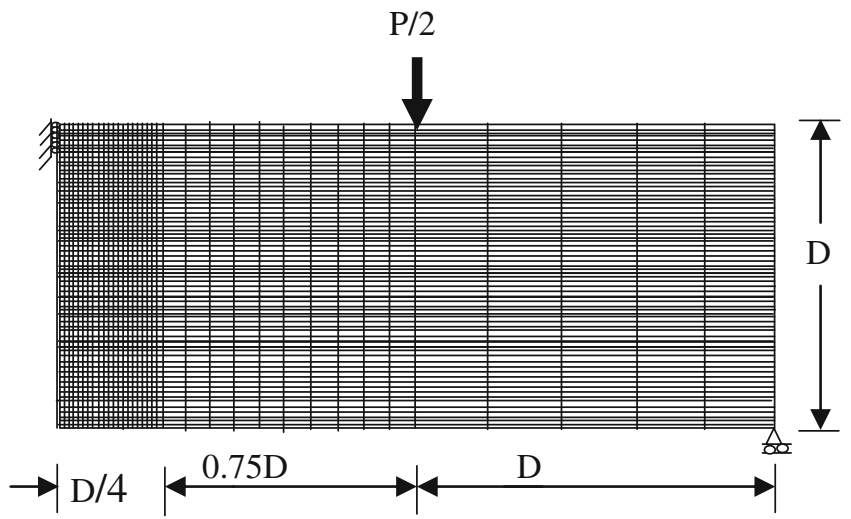

(b) FPBT specimen

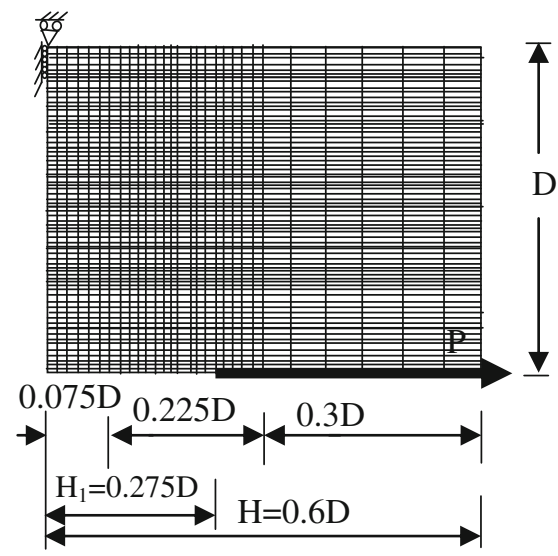

(c) CT specimen

Figure 2. Finite element discretization.

Four-noded isoparametric plane element is considered for finite element calculation. The COD vector is partitioned according to the enhanced algorithm introduced by Planas \& Elices (1991). Finally, the system of nonlinear simultaneous equation is developed and solved using Newton- 
Raphson method. The concrete mix for which $f_{t}=3.21 \mathrm{MPa}, E=30 \mathrm{GPa}, G_{F}=103 \mathrm{~N} / \mathrm{m}$, maximum size of aggregates $d_{a}=16 \mathrm{~mm}$ and Poisson's ratio $v=0.18$ along with quasiexponential softening function (Planas \& Elices 1990) are taken into account for the present investigation. For standard TPBT, FPBT and CT specimens with $B=100 \mathrm{~mm}$ having size range $D=100-600 \mathrm{~mm}$, the finite element analysis is carried out for which the half of the specimens are discretized due to symmetry as shown in figure 2 and 80 numbers of equal isoparametric four-node plane elements are considered along the dimension D.

Two well-known relations of FCM i.e., the characteristic length $l_{c h}=E G_{F} / f_{t}^{2}$ and the critical value of stress intensity factor $K_{C}=\sqrt{ }\left(G_{F} E\right)$ are also used in the comparison of numerical investigation.

\section{Numerical computations}

For precise numerical investigation, the effect of self-weight in TPBT and FPBT geometries can be accounted for at all computation stages whereas this effect cannot be obviously considered for the CT specimen. In the TPBT and FPBT specimens, the input data are gained using the developed FCM which accounts for the effect of self-weight of the beam. Therefore, the FCM yields the external load $P$ without inclusion of the self-weight whereas the crack mouth opening displacement (CMOD) consists of the contribution of the self-weight. Hence, in addition to the external load $P$ acting on the TPBT and FPBT, the influence due to a concentrated load equal to $w_{g} . S / 2$ ( $w_{g}$ being the self-weight of the beam per unit length) and acting at the mid span, is also effective during all stages of the computations. This yields precise comparison amongst the fracture parameters between the two specimen geometries (TPBT and CT) and the two loading conditions (TPBT and FPBT) considered in the study. The details of calculation procedure are outlined elsewhere (Kumar \& Barai 2008, 2009b, 2010a).

The peak load $P_{u}$ and corresponding CMOD $\left(\mathrm{CMOD}_{\mathrm{c}}\right)$ or crack opening displacement (COD) $\left(\mathrm{COD}_{\mathrm{c}}\right)$ for $a_{o} / D$ ratio 0.3 and specimen size range $100-600 \mathrm{~mm}$ obtained using FCM for the TPBT, FPBT and CT specimen geometries as presented in table 1 are employed to evaluate the double- $K$ fracture parameters.

The double- $K$ fracture parameters are computed using the weight function approach having five terms (Kumar \& Barai 2008, 2009b, 2010a). A trial-and-error method is used for calculation of critical value of effective crack extension $a_{c}$ for all the three types of specimens using linear asymptotic superposition assumption. The same quasi exponential softening function is employed in whole calculation for which a comprehensive computer program is developed using MATLAB.

Table 1. The peak load and corresponding crack opening displacement gained using FCM.

\begin{tabular}{lcccccccc}
\hline $\mathrm{D}(\mathrm{mm})$ & \multicolumn{2}{c}{ TPBT geometry } & & \multicolumn{2}{c}{ FPBT geometry } & & \multicolumn{2}{c}{ CT specimen } \\
\cline { 2 - 3 } & $\mathrm{P}_{\mathrm{u}}(\mathrm{kN})$ & $\mathrm{CMOD}_{\mathrm{c}}(\mathrm{mm})$ & & $\mathrm{P}_{\mathrm{u}}(\mathrm{kN})$ & $\mathrm{CMOD}_{\mathrm{c}}(\mathrm{mm})$ & & $\mathrm{P}_{\mathrm{u}}(\mathrm{kN})$ & $\mathrm{COD}_{\mathrm{c}}(\mathrm{mm})$ \\
\hline 100 & 3934.5 & 0.0411 & & 7428.3 & 0.0427 & & 4378.1 & 0.0457 \\
200 & 6571.4 & 0.056 & & 12319 & 0.0602 & & 7427 & 0.0645 \\
400 & 10405 & 0.0797 & & 19383 & 0.0808 & & 12212 & 0.0926 \\
600 & 13034 & 0.101 & & 24224 & 0.1019 & & 16105 & 0.117 \\
\hline
\end{tabular}




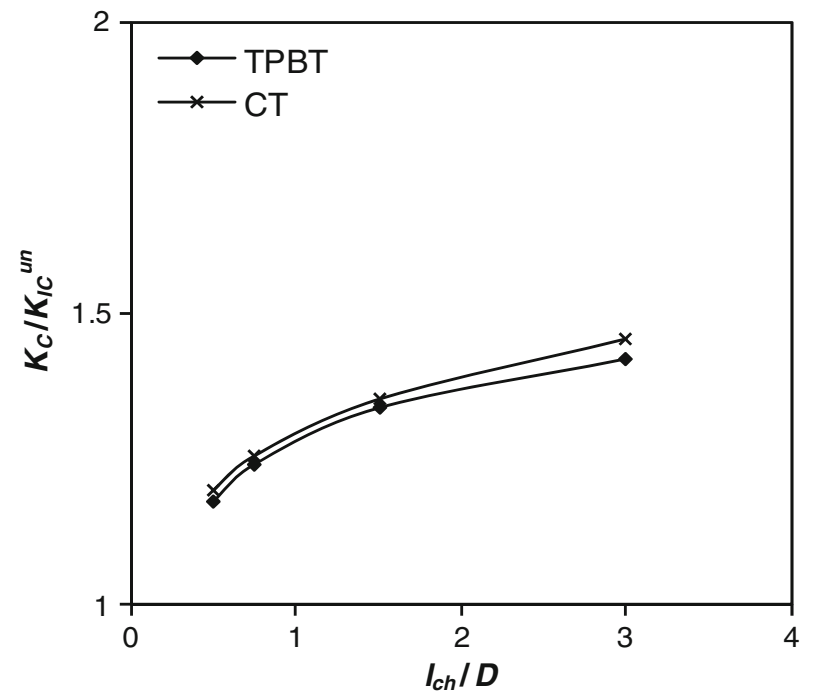

Figure 3. Effect of specimen geometries on $K_{I C}^{u n}$ for different specimen sizes.

\section{Influence of specimen geometry and size-effect on the fracture parameters}

The values of unstable fracture toughness $K_{I C}^{u n}$, cohesive toughness $K_{I C}^{C}$ and initial cracking toughness $K_{I C}^{i n i}$ are calculated using five terms weight function approach for size ranging between 100 and $600 \mathrm{~mm}$ for TPBT and CT test specimen geometries at $a_{o} / D$ ratio of 0.3 . Variations of non-dimensional parameters $K_{C} / K_{I C}^{u n}, K_{C} / K_{I C}^{C}$ and $K_{C} / K_{I C}^{i n i}$ with $l_{c h} / D$ for both the specimen shapes are plotted in figures 3,4 and 5 , respectively.

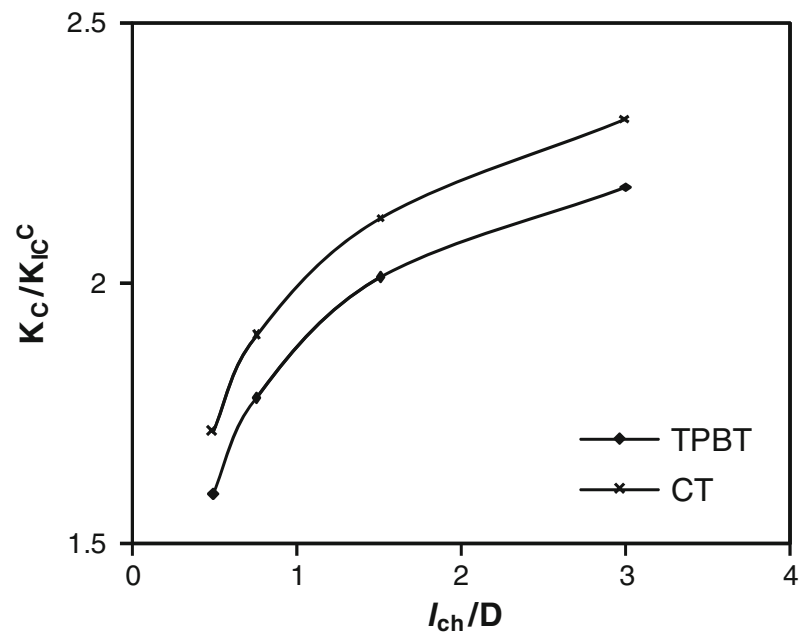

Figure 4. Effect of specimen geometries on $K_{I C}^{C}$ for different specimen sizes. 


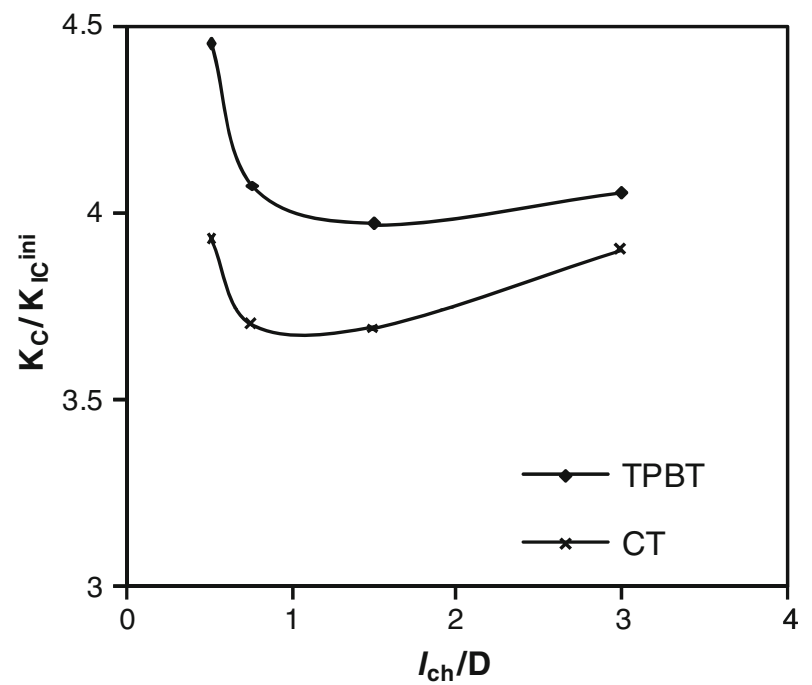

Figure 5. Effect of specimen geometries on $K_{I C}^{i n i}$ for different specimen sizes.

It is observed from the figures that the values of fracture parameters are marginally dependent on the types of specimen geometry. Both the parameters $K_{I C}^{u n}$ and $K_{I C}^{C}$ increase with increase in specimen size whereas the values of $K_{I C}^{i n i}$ are relatively less dependent on the sizes ranging $100-400 \mathrm{~mm}$. However, beyond the size range $400 \mathrm{~mm}$, a decrease in the value of $K_{I C}^{i n i}$ is observed. Furthermore, it is also found that the values of $K_{I C}^{u n}$ for CT specimen are less than those obtained for TPBT specimen by about 2.33, 1.12, 1.33 and $1.71 \%$ for the specimen sizes 100, 200, 400 and $600 \mathrm{~mm}$, respectively. The values of cohesion toughness determined show that the these values for CT specimen are less than those obtained for TPBT geometry by about 5.68, $5.47,6.32$ and $7.07 \%$ for specimen sizes $100,200,400$ and $600 \mathrm{~mm}$ respectively. Consequently, the values of $K_{I C}^{i n i}$ determined as such for TPBT geometry are less than those obtained for CT specimen by nearly 3.47, 6.93, 9.19 and $11.71 \%$ for specimen sizes 100, 200, 400 and $600 \mathrm{~mm}$, respectively.

A similar investigation was presented by the authors (Kumar \& Barai 2008) in which the fracture parameters were calculated at different $a_{o} / D$ ratios ranging from 0.3 to 0.5 for each specimen size. It was observed that these fracture parameters were marginally affected by the value $a_{o} / D$ ratio hence the mean values of the fracture parameters $K_{I C}^{u n}, K_{I C}^{C}$ and $K_{I C}^{i n i}$ were obtained neglecting the influence of $a_{o} / D$ ratio for a particular specimen size. From the study, it was reported that the values of $K_{I C}^{u n}$ for CT specimen were less than those obtained for TPBT specimen by about $2.99,1.69,1.20$ and $1.16 \%$ for sizes $100,200,400$ and $600 \mathrm{~mm}$, respectively. The mean values of $K_{I C}^{C}$ for CT specimen were less than those obtained for TPBT geometry by about 4.59, 4.43, 5.01 and $5.82 \%$ for specimen sizes 100, 200, 400 and $600 \mathrm{~mm}$, respectively. As a result, the average values of $K_{I C}^{i n i}$ for TPBT geometry were less than those obtained for CT specimen by nearly 0, 3.33, 6.55 and $9.63 \%$ for specimen sizes 100, 200, 400 and $600 \mathrm{~mm}$, respectively. 


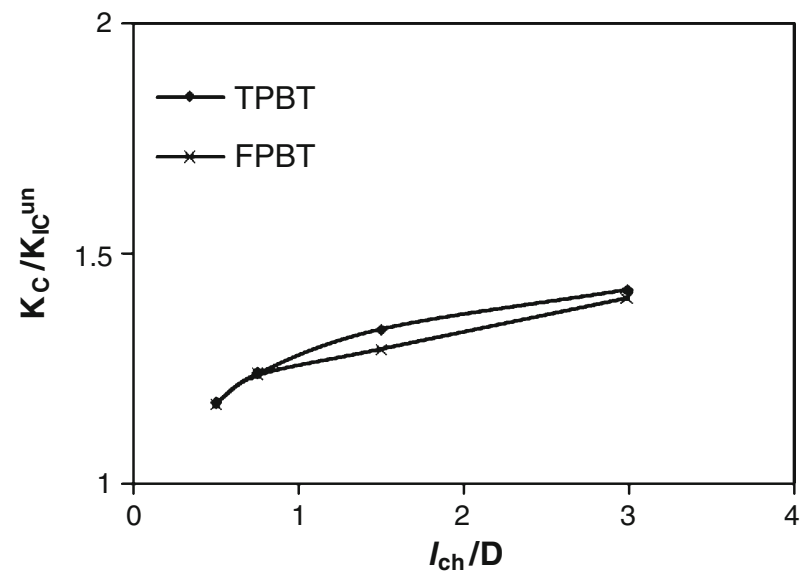

Figure 6. Effect of loading condition on $K_{I C}^{u n}$ for different specimen sizes.

\section{Influence of loading condition and size-effect on the fracture parameters}

The gained values of $K_{I C}^{u n}, K_{I C}^{C}$, and $K_{I C}^{i n i}$ using five terms weight function approach for different specimen sizes ranging between 100 and $600 \mathrm{~mm}$ for TPBT and FPBT loading conditions for $a_{o} / D$ ratio 0.3 are plotted in figures 6,7 and 8 , respectively.

It is observed from the figures that the values of fracture parameters are marginally dependent on the type of loading conditions. It is found that the absolute difference in the values of $K_{I C}^{u n}$ between the two loading conditions is about 1.26, 3.26, 0.30 and $0.08 \%$ for sizes $100,200,400$ and $600 \mathrm{~mm}$, respectively. The values of cohesion toughness determined show that the absolute

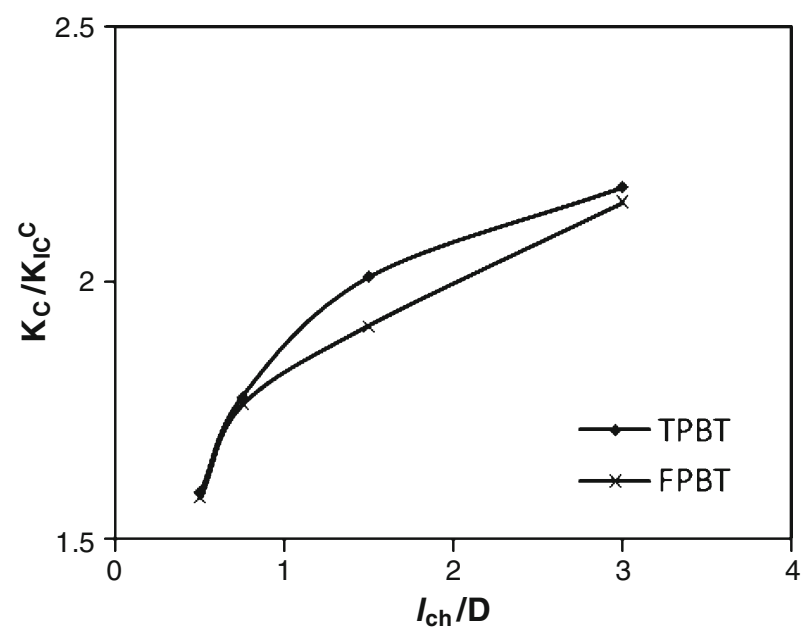

Figure 7. Effect of loading condition on $K_{I C}^{C}$ for different specimen sizes. 


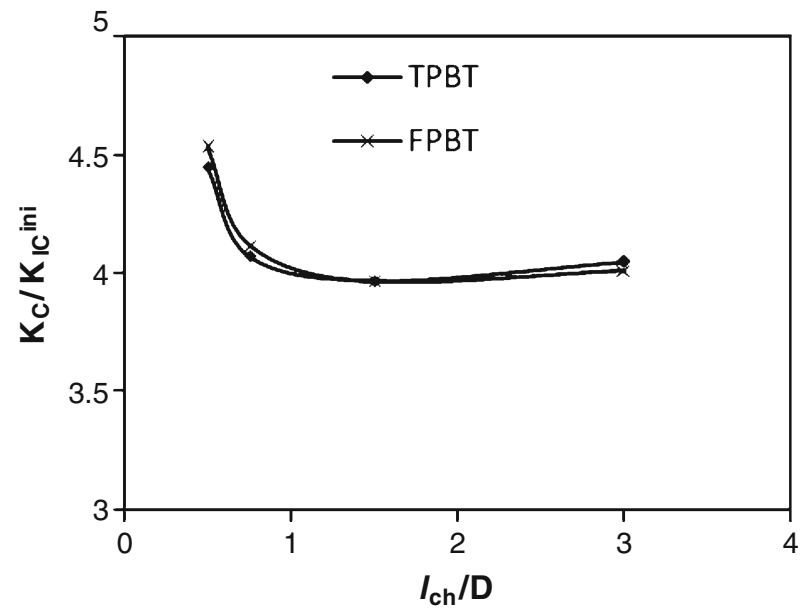

Figure 8. Effect of loading condition on $K_{I C}^{i n i}$ for different specimen sizes.

difference in the values of $K_{I C}^{C}$ for these loading conditions are about 1.42, 4.80, 0.90 and $1.85 \%$ for specimen sizes 100, 200, 400 and $600 \mathrm{~mm}$, respectively. Consequently, the values of $K_{I C}^{i n i}$ determined as such for the two loading conditions are differed by nearly $0.95,0.06,1.12$ and $1.86 \%$ for specimen sizes 100, 200, 400 and $600 \mathrm{~mm}$, respectively.

Kumar \& Barai (2009b) carried out a similar study of the effect of loading condition on the double- $K$ fracture parameters for the specimen size range $100 \leq \mathrm{D} \leq 400 \mathrm{~mm}$ and $a_{o} / D$ ratio ranging from 0.3 to 0.5 . It was observed that the double- $K$ fracture parameters were influenced by size-effect, initial crack-length/depth ratio and type of loading condition. Neglecting the effect of $a_{o} / D$ ratio, the mean values of $K_{I C}^{u n}$ and $K_{I C}^{i n i}$ for TPBT and FPBT specimens for a particular specimen size were computed. It was found that the maximum absolute difference in the value $K_{I C}^{u n}$ between the two loading conditions was less than $2 \%$ and that in the value $K_{I C}^{i n i}$ was less than $3.5 \%$ for specimen size-range $100-400 \mathrm{~mm}$.

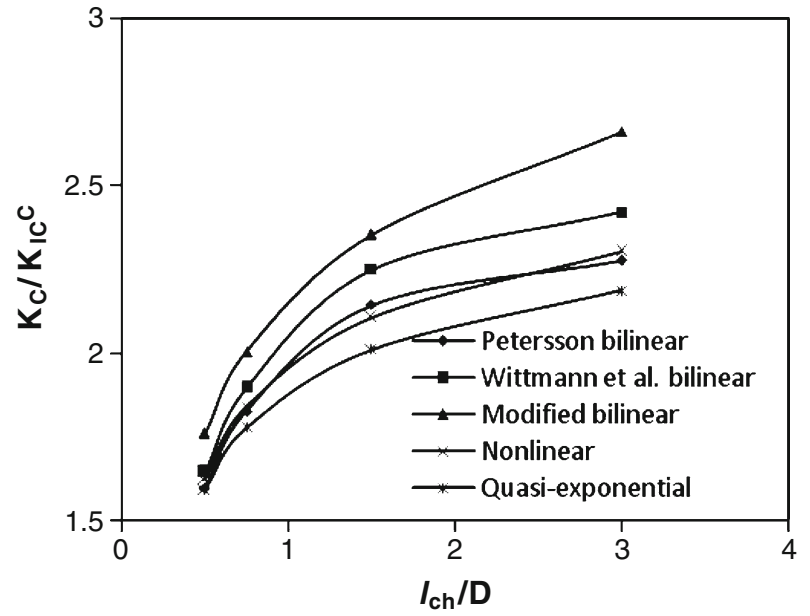

Figure 9. Effect of softening function on $K_{I C}^{C}$ for different specimen sizes for TPBT. 


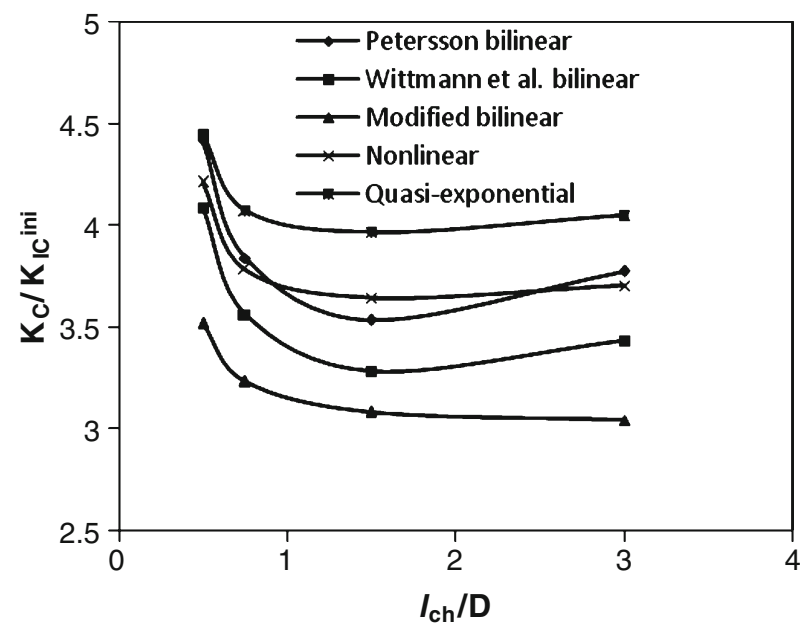

Figure 10. Effect of softening function on $K_{I C}^{i n i}$ for different specimen sizes for TPBT.

\section{Influence of softening function on the fracture parameters}

It is clear that the cohesive stress distribution is not involved in computation of $K_{I C}^{u n}$ of double$K$ fracture criterion hence these values are unaffected by the choice of the softening functions of concrete. Also, it has been reported in the literature that the influence of shapes of softening relations on the calculation of the cohesion toughness are not observable. In the present study, some of commonly used softening functions such as: Petersson (1981) bilinear, Wittmann et al (1988) bilinear, modified bilinear (Xu \& Reinhardt 1999b), nonlinear softening functions (Reinhardt et al 1986) and quasi-exponential (Planas \& Elices 1990) are employed to obtain the $K_{I C}^{C}$ and $K_{I C}^{i n i}$ for the TPBT specimen at $a_{o} / D$ ratio 0.3 for size range $100-600 \mathrm{~mm}$. The non-dimensional forms of the gained results of $K_{I C}^{C}$ and $K_{I C}^{i n i}$ are plotted in figures 9 and 10, respectively. The figures show that these fracture parameters are somewhat influenced by the softening function of concrete.

\section{Conclusions}

A precise numerical study was carried out in the present work to show the effect of various parameters on the double- $K$ fracture parameters. These parameters are mainly involved while characterizing the material fracture parameters. From the investigation, the summary of the present work done can be highlighted as given below.

- The double- $K$ fracture parameters are influenced by many factors such as specimen geometry, loading condition, size-effect and softening function of concrete. The influence of shape of test specimen and type of loading condition is relatively less than the size-effect on the values of fracture parameters.

- For specimen size range $(100 \leq \mathrm{D} \leq 600 \mathrm{~mm})$ considered in the study, the maximum difference in the values of $K_{I C}^{u n}, K_{I C}^{C}$ and $K_{I C}^{i n i}$ between the two specimen geometries TPBT and CT specimen are about 2, 7 and $12 \%$ whereas these difference between the two loading conditions TPBT and FPBT are about 3, 5 and $2 \%$, respectively. 


\section{References}

ASTM International Standard E399-06 2006 Standard Test Method for Linear-Elastic Method Plane-Strain Fracture Toughness $\mathrm{K}_{I C}$ of Metallic Materials. Copyright ASTM International, West Conshohocken, U.S.:1-32

Bažant Z P, Kim J-K, Pfeiffer P A 1986 Determination of fracture properties from size effect tests. J. Struct. Eng. ASCE 112:289-307

Bažant Z P, Oh B H 1983 Crack band theory for fracture of concrete. Mater. Struct. 16(93):155-177

Carpinteri A 1989 Decrease of apparent tensile and bending strength with specimen size: two different explanations based on fracture mechanics. Int. J. Solids Struct. 25:407-429

Hillerborg A, Modeer M, Petersson P E 1976 Analysis of crack formation and crack growth in concrete by means of fracture mechanics and finite elements. Cem. Concr. Res. 6:773-782

Jenq Y S, Shah S P 1985 Two parameter fracture model for concrete. J. Eng. Mech., ASCE 111(10): $1227-1241$

Kumar S, Barai S V 2008 Influence of specimen geometry on determination of double- $K$ fracture parameters of concrete: A comparative study. Int. J. Fract. 149:47-66

Kumar S, Barai S V 2009a Determining double- $K$ fracture parameters of concrete for compact tension and wedge splitting tests using weight function. Eng. Fract. Mech. 76:935-948

Kumar S, Barai S V 2009b Influence of loading condition and size-effect on the $\mathrm{K}_{R}$-curve based on the cohesive stress in concrete. Int. J. Fract. 156:103-110

Kumar S, Barai S V 2009c Effect of softening function on the cohesive crack fracture parameters of concrete CT specimen. Sadhana-Acad. Proc. Eng. Sci. 36(6):987-1015

Kumar S, Barai S V 2010a Determining the double- $K$ fracture parameters for three-point bending notched concrete beams using weight function. Fatigue Fract. Eng. Mater. Struct. 33(10):645-660

Kumar S, Barai S V 2010b Size-effect prediction from the double- $K$ fracture model for notched concrete beam. Int. J. Damage Mech. 19:473-497

MATLAB, Version 7, The Math Works, Inc., Copyright 1984-2004

Nallathambi P, Karihaloo B L 1986 Determination of specimen-size independent fracture toughness of plain concrete. Mag. Concr. Res. 38(135):67-76

Petersson P E 1981 Crack growth and development of fracture zone in plain concrete and similar materials, Report No. TVBM-100, Lund Institute of Technology

Planas J, Elices M 1990 Fracture criteria for concrete: mathematical validations and experimental validation. Eng. Fract. Mech. 35:87-94

Planas J, Elices M 1991 Nonlinear fracture of cohesive material. Int. J. Fract. 51:139-157

Reinhardt H W, Cornelissen H A W, Hordijk D A 1986 Tensile tests and failure analysis of concrete. J. Struct. Eng., ASCE 112(11):2462-2477

RILEM Draft recommendation (50-FMC) 1985 Determination of the fracture energy of mortar and concrete by means of three-point bend test on notched beams. Mater. Struct. 18:285-290

Wittmann F H, Rokugo K, Bruhwiller E, Mihashi H, Simopnin P 1988 Fracture energy and strain softening of concrete as determined by compact tension specimens. Mater. Struct. 21:21-32

Xu S, Reinhardt H W 1998 Crack extension resistance and fracture properties of quasi-brittle materials like concrete based on the complete process of fracture. Int. J. Fract. 92:71-99

Xu S, Reinhardt H W 1999a Determination of double- $K$ criterion for crack propagation in quasi-brittle materials, part I: experimental investigation of crack propagation. Int. J. Fract. 98:111-149

Xu S, Reinhardt H W 1999b Determination of double- $K$ criterion for crack propagation in quasi-brittle materials, part II: analytical evaluating and practical measuring methods for three-point bending notched beams. Int. J. Fract. 98:151-177

Xu S, Reinhardt H W 1999c Determination of double- $K$ criterion for crack propagation in quasibrittle materials, part III: compact tension specimens and wedge splitting specimens. Int. J. Fract. 98: 179-193

Xu S, Reinhardt H W 2000 A simplified method for determining double- $K$ fracture meter parameters for three-point bending tests. Int. J. Fract. 104:181-209 
Xu S, Zhang X 2008 Determination of fracture parameters for crack propagation in concrete using an energy approach. Eng. Fract. Mech. 75:4292-4308

Xu S, Zhu Y 2009 Experimental determination of fracture parameters for crack propagation in hardening cement paste and mortar. Int. J. Fract. 157:33-43

Zhang X, Xu S, Zheng S 2007 Experimental measurement of double- $K$ fracture parameters of concrete with small-size aggregates. Frontiers Archit. Civ. Eng. China 1(4):448-457

Zhao Y and Xu S 2002 The influence of span/depth ratio on the double- $K$ fracture parameters of concrete. J. China Three Georges Univ (Nat. Sci.) 24(1):35-41 